\title{
Research on the Teaching Reform of the Course of Commodity Science of the Chain Management Group
}

\author{
Song Chuanzhen
}

School of Business Administration, Shandong Women's University, Jinan, Shandong, China

31891575@qq.com

\begin{abstract}
"Commodity Studies" is an important basic course for the chain operation and management professional group. It has strong applicability and practicality. The teaching content of this course is complex, but the number of hours for the basic basic course is less, plus some experimental training equipment The lack of teaching methods is relatively single, which leads to the poor teaching effect of "Commodity Studies", which can not adapt well to the requirements of the chain management professional group. This article discusses the necessity of teaching "Commodity Science" and its teaching status and deficiencies in the chain operation management group, and attempts to reform and explore the teaching of "Commodity Science" in the chain operation management group. The training requirements are oriented, the teaching content is restructured, diversified teaching methods are used, and the relevant teaching conditions are improved to improve the teaching effect of "Commodity Science".
\end{abstract}

Keywords: commodity science, chain management, teaching research

\section{连锁经营管理专业群《商品学》课程教学改革研究}

\author{
宋传珍
}

山东女子学院工商管理学院, 济南, 山东, 中国

31891575@qq.com

\section{摘要}

《商品学》作为连锁经营管理专业群重要的基础课, 其应用性和实践性较强, 该课程教学内容繁杂, 但作为专业基础课课时设置较少, 再加上部分实验实训设备缺乏, 教学方法也相对单一，导致《商品 学》教学效果不佳, 无法很好地适应连锁经营管理专业群的要求。本文通过对连锁经营管理专业群开 设《商品学》的必要性及其教学现状与不足展开讨论, 尝试对连锁经营管理专业群《商品学》课程的 教学进行改革探索, 认为应该以教学目标及能力培养要求为导向, 重构教学内容, 采用多样化的教学 方法, 完善相关教学条件, 从而改善《商品学》教学效果。

关键词: 商品学; 连锁经营; 教学研究

\section{1. 连锁经营管理专业群开设《商品学》课程的 必要性}

连锁经营管理专业群依托连锁经营行业, 将工商管 理、市场营销、物流管理、人力资源管理等各专业按照 企业各职能岗位类型进行组合打包, 为连锁企业输送各 岗位需求人才。在连锁经营管理专业群相关专业中, 《商 品学》作为专业基础课程开设, 其内容以商品质量为中 心, 综合多学科基础知识, 主要研究商品使用价值及其 实现规律, 通过该课程的学习, 让学生了解商品学基础 知识, 初步具备工作中对商品管理和经营问题的处理能
力。

各大院校管理类专业在上世纪九十年代以前普遍 开设了《商品学》课程, 但是随着经济环境和社会需求 的不断变化, 管理类专业的人才培养目标发生了变化, 课程体系也不断进行着调整, 《商品学》逐渐被《创新 创业教育》、《现代企业管理》等更能体现社会需求的课 程所取代。时至今日, 大部分院校管理类专业已不再开 设《商品学》课程, 像市场营销、物流管理等少数仍然 设有《商品学》课程的专业授课学时也有不同程度的压 缩, 授课内容也仅仅针对商品的社会属性。

实际上, 在连锁经营企业中, 像采购、营销、配送、 仓库管理甚至是门店的经营管理等职能工作都与商品 直接相关, 在管理类学生中开设《商品学》课程具有较 


\section{3. 连锁经营管理专业群《商品学》教学改革}

学生在大学中初步学习一些关于商品的基本理论、基础 知识、基本技能, 能够有效弥补这些学生在商品学理论 知识上的不足, 为连锁经营管理专业群其他专业课程的 学习打下良好的基础, 也有利于提高学生的实践能力。

\section{2. 连锁经营管理专业群《商品学》课程设置存 在的问题}

《商品学》作为连锁经营管理专业群的基础课程, 其教材的选取一般为《商品学概论》或《商品学基础》 等, 教学内容侧重于商品使用价值的实现, 如商品分类、 商品品种、商品质量影响因素及其质量管理方法、商品 标准、商品检验及认证、储运商品管理等方面的内容, 虽然看上去内容丰富, 但只是基本概念和基本理论的陈 述, 实操性较差, 显然与连锁经营企业职能要求缺乏契 合性。当前连锁经营管理专业群《商品学》课程教学中 存在的问题主要表现在以下几个方面:

\section{1. 《商品学》教学重理论轻实践}

连锁经营管理专业群所针对的是整个企业经营管 理体系, 涉及商品采购、商品管理、包装、质量检验、 商品陈列等, 特别注重实践性和可操作性, 而《商品学》 教学内容繁杂, 虽然从商品分类到商品储运等环节涉及 的比较全面, 但其强调理论知识的传授, 实践性较差, 甚至很多专业《商品学》课程中无实践学时的设置, 这 样就导致《商品学》教学内容无法很好地适应连锁经营 管理专业群要求。

\section{2. 《商品学》教学形式单一}

连锁经营管理专业群《商品学》课程设置一般为 36 课时, 课时有限, 而授课章节、课程内容繁多, 传统教 学中一般是以教师讲授理论知识为主, 部分内容会增加 音视频资料辅助学习, 但因为课时的限制, 较少时间安 排课堂案例分析、课堂讨论这样的环节, 与学生的互动 也基本以教师提问的形式进行, 学生参与少, 课堂气氛 不活跃, 学习效果不佳。

\section{3. 实验实训条件和设备不足}

《商品学》本身是一门涉及多学科、实践性和应用 性较强的课程, 某些环节的授课如商品检验等需要一些 必备的实验仪器设备等作为支撑。但目前很多学校《商 品学》的实验实训课程只是一些软件的操作, 让学生简 单走一遍流程, 实践性较差, 还有一些专业完全不具备 校内实训条件, 校外实训也多以毕业实习为主, 管理松 散, 无法实现该课程实践教学的需要。
从以上分析不难看出, 目前在连锁经营管理专业群 开设《商品学》课程存在着一些障碍, 而如何破解这些 阻碍确保《商品学》教学效果是非常值得深思的问题, 笔者认为可以从教学内容的构建和教学方法的多样化 等方面开展相关教学改革。

\section{1. 根据职能要求重新构建教学内容}

连锁经营企业的组织构架一般由连锁总部、配送中 心和连锁门店构成。连锁总部的职能一般是战略制定、 规划设计、营销、展店、财务、人力资源管理等, 配送 中心的职能主要包括采购、配送、分拣、商品管理等, 连锁门店的职能主要是对所管理门店进行相关的商品、 人员、环境等管理。根据连锁企业各职能要求涉及到的 与《商品学》相关的岗位主要有营销、采购、质检、配 送、市场管理、理货、促销员、顾客服务等。连锁经营 管理专业群依托连锁经营行业, 将工商管理、市场营销、 物流管理、人力资源管理各专业按照企业各职能岗位类 型进行组合打包, 为连锁企业输送各岗位需求人才。根 据人才培养的要求, 连锁经营管理专业群的课程内容应 该根据培养连锁企业各职能岗位对知识、能力、素质的 要求进行相应的设置。所以, 我们可以对《商品学》的 教学内容和环节进行重新构建, 根据采购、储运、销售 及标准化管理的要求设计商品分类、商品品种、商品质 量与管理、商品质量标准、商品质量认证、商品检验、 商品包装、商品储存与养护等学习章节, 另外, 针对连 锁经营管理专业群的不同专业, 也可以在该框架结构的 基础上进行重难点的调整, 以更好地满足培养目标, 适 应社会需求。比如在工商管理专业可以侧重于商品质量 管理、商品质量监督、商品质量认证和消费者权益保护 等内容, 在市场营销专业可以侧重于商品分类、商品品 种、商品标准、商品包装等内容，在物流管理专业可以 侧重于商品分类、商品检验、商品包装、储运管理等内 容, 在国贸专业可以侧重于商品标准、商品认证、商品 储运管理等内容。通过《商品学》课程内容的重新构建, 结合多样化的教学方法及实验实训, 让学生在基本知识 方面, 具备从事连锁经营企业管理等工作所必须具备的 商品基本知识, 具有应用商品学知识的初步能力, 能力 方面, 具有运用商品学进一步学习相关专业知识的初步 能力, 培养评价商品质量的水平, 提高介绍商品、鉴别 商品、正确使用商品、保养维护商品的能力, 素质方面, 树立自觉依法保护环境、维护消费者合法权益的科学态 度及质量意识。

\section{2. 根据教学内容选择多样化教学方法}

传统的《商品学》教学模式以单向讲授为主, 教师 主动提供, 学生被动接收, 考核也以期末闭卷考试或课 程论文的形式展开, 导致学生学习积极性和主动性较差, 
尤其是自律性较差的学生仅重视考前的短期突击, 疏于 平时学习状态的管理, 学习效果较差。调动学生学习《商 品学》的主动性和积极性, 需要打破传统的教学模式, 结合内容有针对性地采取多样化的教学方法。

\subsection{1. 案例教学}

在授课过程中结合某个知识点或专题引入相关案 例让学生进行讨论分析是比较常见的一种方法, 教学效 果显著。在《商品学》授课过程中, 教师在教学中要联 系实际, 将衣食住行密切相关的各类商品变为课堂教学 的现成案例, 让学生通过具体化、生活化的案例轻松掌 握相关知识点。其次, 可以通过对一些经典案例进行分 析, 教师提出问题, 组织学生进行深入思考或分组研讨, 让学生置身于充满问题的情境中, 引导学生变被动接收 为主动思考, 深入理解相关知识并将理论知识转化为解 决问题的能力。例如, 在商品标准部分, 可以选用 “农 夫山泉标准门”、“伤人的美瞳” 等事件, 让学生从政府、 企业、消费者等不同角度进行分析, 使学生熟悉我国的 标准体系以及标准的实施和监督状况, 使学生深刻认识 到标准的制定和执行对商品质量的影响, 并能合理选购 不同标准的商品, 维护消费者的合法权益, 再次, 教师 应该提供给学生一些学习平台, 指导学生平时也能充分 利用各种视听资料。比如央视频道的《消费主张》、《每 周质量报告》、《农广天地》等栏目, 在商品分类、商品 标准、商品检验、商品包装、商品质量认证和监督、在 商品储运、商品养护等方面有较多的案例, 可以帮助学 生更好地理解相关的知识点。

\subsection{2. 专题调研}

在《商品学》教学过程中, 教师要紧跟时代发展, 利用社会普遍关注的问题和学生感兴趣的专题, 设定调 研题目, 要求学生分组进行专题调研, 收集相关资料, 必要时进行一手资料的调查, 汇总并形成调查报告, 学 生课堂汇报, 教师提出相关问题并进行点评。比如食品 安全问题一直是社会普遍关注的问题, 可以让学生围绕 感兴趣的点对食品质量安全的影响因素、食品卫生标准、 国家相关法律法规及其实施监督状况进行调研, 谈一谈 对中国食品安全问题的看法; 在学习商品分类与编码时, 可以让学生通过实地调查, 比较不同超市或便利店在商 品分类和编码方面的异同点以及各自的优缺点, 并提出 相应的优化方案; 针对 2020 年疫情防控期间, 对口罩 和消毒用品销售情况进行调研, 结合个别企业销售高价 口罩、假冒伪劣口罩的行为, 分析假冒伪劣商品产生的 原因及其对人类和社会造成的危害, 应如何对假冒伪劣 商品进行辨别, 并尝试提出防治措施。一个专题往往会 涉及多个章节的内容, 调研和汇报的过程可以锻炼学生 逻辑思辨、团队合作和语言组织的能力, 帮助其更好地 从整体上把握《商品学》相关内容。

\subsection{3. 翻转课堂}

传统的教学模式中, 教师占据主导权, 以课堂讲授 为主, 学生课上接收新课内容, 课下做作业进行巩固, 无法更好地针对学生个体对知识接收消化的差异, 教学 无法达到理想的效果。所谓翻转课堂, 是指重新调整课 堂内外的时间, 将学习的主动权从教师转移给学生。在

《商品学》的教学中也可以利用翻转课堂, 在课前教师 将需要学生提前学习的文档内容打包发给学生自主学 习, 文档内容包含教学目标、教学重点难点、教学内容、 思考题、相关支撑音视频文件等, 学生根据个人情况可 反复观看学习并整理好自己的问题; 课上的时间, 教师 深入与学生交流, 辅导答疑; 课后可通过案例分析、调 研报告等形式对教学效果进行及时评价, 掌握学生对相 关教学内容的理解和运用情况, 查漏补缺。

\section{2. 4. 直观演示}

当讲授的学生不熟悉或较难理解的知识点时, 可 以借用具体的实物进行分析, 比如商品代码及条形码 部分, 可以充分利用每位学生手中的签字笔、图书等实 物的条形码进行讲解, 使同学们有一个直观的认识和理 解, 从而更好的掌握编码的规则、各部分代码的含义以 及条形码的结构。在商品质量认证部分, 可以让学生提 前准备方便携带的日用品、食品、工业品等的外包装, 对不方便携带产品包装的, 可以充分利用图片、影音资 料等指导学生识别商品包装上的各种质量认证标志, 帮 助学生更好地理解和掌握各个质量认证标志的适用范 围、作用、主要原则以及如何通过商品质量认证打破贸 易技术壁垒等内容。

另外, 对于课堂上很难直观演示的部分, 比如商品 分类、商品检验、商品储运管理等, 可以通过实习实训 来实现, 带领学生到超市、物流公司等企业进行参观见 习或现场教学, 增加学生直观感受, 深化对知识的理解 掌握。

\section{3 根据实践要求加强实验实训教学}

《商品学》是一门实践性和应用型较强的课程, 为 了更好地满足连锁经营企业岗位需求, 需要《商品学》 课程应设置一定比例的实验实训课时, 同时在校内实验 室建设和校外实训基地建设方面提供相应支撑。

校内实践方面, 以文科为重的院校很难专门为《商 品学》去建立一个实验室, 尤其是商品检验、商品包装、 商品储运等方面的专业实验设备购置更是不现实, 校内 实验实训要多依托专业群各专业原有的实验室及相关 设施设备, 如充分利用物流管理实验室、工商企业管理 实验室、市场营销实验室, 在此基础上, 可以购置连锁 经营管理及商品学相关软件, 为学生提供上机实践平台, 让学生能够通过校内实验实训条件基本了解连锁经营 企业运营流程及商品管理的基本知识, 引导学生正确使 
用信息技术，以帮助他们在将来的工作岗位上运用信息 技术实现对商品的管理, 实现商品的使用价值。

对于因校内实验实训条件限制而无法达到教学目 标的部分, 可以充分利用校外实践来完成。首先, 需要 加强校外实习基地的建设, 尤其是加强和大型连锁经营 企业建立校企合作关系, 利用一部分课时及周末时间带 学生到企业进行见习, 通过现场的授课及参观, 让学生 更直观地了解商品相关的操作, 加强直观感受, 积累经 验。其次, 要充分利用学生的专业实习和毕业实习, 让 学生在实习岗位进一步加深对商品学知识的认知, 强化 包装、检验、储运等实践内容。再次, 坚持 “走出去、 请进来” 的原则, 让授课教师深入企业一线进行顶岗实 践, 同时设置企业课堂, 聘请行业专家和管理人员为为 学生授课, 结合企业实际拓展学生视野, 进一步激发学 生们的探索意识和创新精神, 提高其解决现实问题的能 力。

总之, 连锁经营管理专业群《商品学》教学应以连 锁经营岗位职业能力要求为导向重构教学内容, 以混合 式、多样化的教学方法导入教学内容, 在注重培养学生 职业素质的同时, 依托连锁经营企业加强实验实训教学, 帮助学生提升专业技能。

\section{REFERENCES}

[1] Wan R. (2016) Introduction to Commodity Science (Sixth Edition). China Renmin University Press, Beijing.

[2] Wang Y, Jin X, Zhao L.J, et al. (2012) Application research of behavior-oriented teaching method in the course of "Commodity Science". Journal of Social Science of Jiamusi University, 1:171-172.

[3] Yang M.F, Tao L.L. (2015) Study on the Teaching Practice of Commodity Science in Higher Vocational Chain Management Major [J]. Curriculum Education Research, 34:244-245.

[4] Zhang S.H. (2019) Research on Reconstructing Commodity Curriculum Ability System and Improving Its Professional Practicability. Logistics Engineering and Management, 41:151-154.

[5] Yu L.Y. (2019) Exploration of classroom teaching reform of "Introduction to Commodity Studies" based on flipped classroom. Theoretical Research and Practice of Innovation and Entrepreneurship, 24:64-65. 